\title{
Comparative Analyses of Coding and Noncoding DNA Regions Indicate that Acropora (Anthozoa: Scleractina) Possesses a Similar Evolutionary Tempo of Nuclear vs. Mitochondrial Genomes as in Plants
}

\author{
I.-Ping Chen • Chung-Yu Tang • Chih-Yung Chiou • \\ Jia-Ho Hsu • Nuwei Vivian Wei • Carden C. Wallace • \\ Paul Muir • Henry Wu Chaolun Allen Chen
}

Received: 4 December 2007 / Accepted: 20 June 2008 /Published online: 1 August 2008

(C) Springer Science + Business Media, LLC 2008

\begin{abstract}
Evidence suggests that the mitochondrial (mt) DNA of anthozoans is evolving at a slower tempo than their nuclear DNA; however, parallel surveys of nuclear and mitochondrial variations and calibrated rates of both synonymous and nonsynonymous substitutions across taxa are needed in order to support this scenario. We examined species of the scleractinian coral genus Acropora, including previously unstudied species, for molecular variations in protein-coding genes and noncoding regions of both nuclear and mt genomes. DNA sequences of a calmodulin $(\mathrm{CaM}$ )-encoding gene region containing three exons, two introns and a 411-bp mt intergenic spacer (IGS) spanning the cytochrome $b(c y t b)$ and NADH 2 genes, were obtained from 49 Acropora species. The molecular evolutionary rates of coding and noncoding regions in nuclear and $\mathrm{mt}$ genomes were compared in conjunction with published data, including mt cytochrome $b$, the control region, and
\end{abstract}

I-Ping Chen and Chung-Yu Tang, co-first author (equal contribution)

I.-P. Chen $\cdot$ C.-Y. Tang $\cdot$ C.-Y. Chiou $\cdot$ J.-H. Hsu $\cdot$ N. V. Wei $\cdot$

H. Wu $\cdot$ C. A. Chen $(\bowtie)$

Biodiversity Research Center, Academia Sinica,

Nankang,

Taipei 115, Taiwan

e-mail: cac@gate.sinica.edu.tw

J.-H. Hsu $\cdot$ N. V. Wei • C. A. Chen

Institute of Oceanography, National Taiwan University,

Taipei, 106, Taiwan

C. C. Wallace $\cdot$ P. Muir

Museum of Tropical Queensland,

Townsville,

Queensland Q4810, Australia nuclear Pax-C introns. Direct sequencing of the mtIGS revealed an average interspecific variation comparable to that seen in published data for $\mathrm{mt} c y t b$. The average interspecific variation of the nuclear genome was two to five times greater than that of the mt genome. Based on the calibration of the closure of Panama Isthmus (3.0 mya) and closure of the Tethy Seaway (12 mya), synonymous substitution rates ranged from $0.367 \%$ to $1.467 \% \mathrm{Ma}^{-1}$ for nuclear $C a M$, which is about 4.8 times faster than those of mt cytb $\left(0.076-0.303 \% \mathrm{Ma}^{-1}\right)$. This is similar to the findings in plant genomes that the nuclear genome is evolving at least five times faster than those of mitochondrial counterparts.

Keywords Molecular evolution · Nuclear genes ·

Mitochondrial genes $\cdot$ Scleractinian corals $\cdot$ Acropora .

Calmodulin

\section{Introduction}

A growing body of evidence suggests that the mitochondrial (mt) DNA of anthozoans is evolving at a slow tempo (Medina et al. 1999; van Oppen et al. 1999; Chen and Yu 2000; Shearer et al. 2002; Fukami and Knowlton 2005; Tseng et al. 2005; Hellberg 2006). A comparison of 964 positions of the cytochrome $\mathrm{b}(c y t b)$ gene between two of the three Caribbean Acropora species and seven Pacific species showed only $0.3-0.8 \%$ sequence divergence, equal to a maximum divergence rate of $0.1-0.18 \% \mathrm{Ma}^{-1}$, which is at least ten to 20 times slower than the "standard" vertebrate mtDNA clock (van Oppen et al. 1999). Estimates of sequence divergence within the family Acroporidae 
showed that $\mathrm{mt} 12 \mathrm{~S}$ ribosomal RNA (rRNA) is ten times slower $\left(<0.01 \% \mathrm{Ma}^{-1}\right)$ than the cytb gene (Chen and Yu 2000; Tseng et al. 2005). An even slower evolutionary tempo was observed among three members of the Montastraea annularis complex, for which only $0.03-0.04 \% \mathrm{Ma}^{-1}$ was observed in complete $\mathrm{mt}$ genomes (Fukami and Knowlton 2005). Shearer et al. (2002) concluded that slow evolution and unique genomic characteristics may be common in primitive metazoans and that their patterns of mtDNA evolution differ from those in other animal systems.

This slow characteristic, however, requires parallel surveys of nuclear variations and calibrated rates of both synonymous and nonsynonymous substitutions across taxa in order to put it in a phylogenetic framework. Information on scleractinian mt genomes is increasing (van Oppen et al. 2001; Fukami and Knowlton 2005; Tseng et al. 2005; Medina et al. 2006; Chen et al. 2008). The available data for comparing nuclear variations are confined to ribosomal RNA genes and their spacers, for which it is difficult to estimate particular synonymous and nonsynonymous substitutions of protein-coding genes (reviewed in Shearer et al. 2002). To overcome this limitation, Hellberg (2006) compared the molecular evolution of 630-bp mt cytochrome oxidase I (COI) DNA sequences of 18 populations of Balanophyllia elegans, a solitary coral species known from a population genetic study to have relatively high allozyme variations (Hellberg 1994, 1995). His result was consistent with the characteristics of slow evolution in anthozoan $\mathrm{mt}$ genomes, showing no variations but a low synonymous substitution rate $\left(0.05 \% \mathrm{Ma}^{-1}\right)$, found in B. elegans (Hellberg 2006), however, relative rates and evolutionary tempos between $\mathrm{mt}$ and nuclear genomes were not estimated, since allozymes are the summation of protein variations, which cannot be directly converted to nucleotide substitutions. Additionally, the noncoding regions of nuclear genomes, such as introns, were not estimated.

In this study, we examined the evolutionary tempos of coding and noncoding regions of both $\mathrm{mt}$ and nuclear genomes in the scleractinian genus Acropora. This is by far the largest extant genus of reef-building corals with over 113 valid species (Wallace 1999) and also one of the most widespread, spanning the Indian and Pacific Oceans and the Caribbean. The occurrence of up to 70 Acropora species in sympatry (Veron 1993) and their participation in synchronous mass-spawning events (Harrison et al. 1984; Willis et al. 1985; Babcock et al. 1986) create major opportunities for interspecific hybridization and, hence, introgression (Willis et al. 1997). Because of these ecological and evolutionary characteristics, the molecular evolution of Acropora has been studied extensively (Wei et al. 2006; reviewed in Willis et al. 2006). Previous studies of interspecific divergences among Acropora species revealed rates of mtDNA sequence evolution two-three times slower than those of the single-copy minicollagen nuclear gene and its intron from the same species (Fukami et al. 2000; van Oppen et al. 2001). Further comparisons of rates of synonymous and nonsynonymous substitutions are needed to reveal the full landscape of differentiation in evolutionary tempos between $\mathrm{mt}$ and nuclear genomes in Acropora.

In order to survey nucleotide variations from nuclear protein-coding genes, we characterized the gene structure of the calmodulin $(\mathrm{CaM})$-encoding genea calcium $\left(\mathrm{Ca}^{2+}\right)$ binding protein which plays an important role in many cellular organization and signal transduction pathways (Friedberg and Rhoads 2001) in Acropora muricata. This showed that $A$. muricata $C a M$ is a single-copy gene which possesses a four-intron structure, the ancestral organization for eumetazoans (Chiou et al. 2008). The exons and introns of $C a M$ provided the molecular information necessary for comparing the evolutionary rates of the nuclear and $\mathrm{mt}$ genomes. In addition, published data of $\mathrm{Pax}-\mathrm{C}$ intron were used in comparison as well. For the $\mathrm{mt}$ genome counterpart, we sequenced the intergenic spacer $(I G S)$, the largest spacer spanning cytochrome $b(c y t b)$ and NADH 2 (NAD2) in the Acropora mt genome (van Oppen et al. 2001) for noncoding region comparisons and also used in published data on the $c y t b$ and $\mathrm{mt}$ control regions.

\section{Materials and Methods}

\section{Sample Collection}

The study used 48 species from 15 species groups including four major clades of Acropora (Wallace 1999) plus $A$. pichoni, A. cf divaricata, A. dendrum, A. derawanensis, and A. kirstyae, with four species of Isopora as the outgroup because Isopora is sister group to Acropora, shown in phylogenetic analyses using morphological, reproductive, and molecular characters (Wallace et al. 2007; Table 1). Samples of $A$. valida were from Penghu, Taiwan and $A$. palmata and $A$. cervicornis were from Panama; all other species were from the Great Barrier Reef of Australia or Indonesia, with voucher specimens deposited in the Museum of Tropical Queensland, Australia.

DNA Extraction, Amplification, Cloning, and Sequencing

Coral DNA was extracted from preserved Acropora branches using a plant genomic DNA extraction miniprep system (VIOGENE, Taipei). Small pieces of skeleton containing tissue (1-2 g) were ground into powder using liquid nitrogen. The extraction process followed the manufacturer's protocol. The extraction efficiency was examined with 1\% LE Agarose (SAMBREX) gel electrophoresis in 
Table 1 Acropora species groups, species, length of calmodulin and mitochondrial intergenic spacer characterized in this study, and the GenBank accession numbers

\begin{tabular}{|c|c|c|c|c|c|c|c|c|}
\hline \multirow[t]{2}{*}{ Species group } & \multirow[t]{2}{*}{ Species } & \multicolumn{4}{|c|}{$C a M(b p)$} & \multirow{2}{*}{$\frac{\text { GenBank }}{\text { Accession no. }}$} & \multirow{2}{*}{$\frac{I G S(\mathrm{bp})}{\text { Total length }}$} & \multirow{2}{*}{$\frac{\text { GenBank }}{\text { Accession no. }}$} \\
\hline & & Exons & Intron 2 & Intron 3 & Total length & & & \\
\hline A. humilis A & A. digitifera & 410 & $383-384$ & $128-404$ & $922-1197$ & EU534169-70 & - & - \\
\hline \multirow[t]{4}{*}{ A. nasuta A } & A. cerealis & - & - & - & - & - & 410 & EU533979 \\
\hline & A. valida & 410 & $369-380$ & $403-405$ & $1184-1193$ & EU534165-68 & 410 & EU534047 \\
\hline & A. nasuta & - & - & - & - & - & 410 & EU534032 \\
\hline & A. lutkeni & 410 & 377 & 403 & 1190 & EU534141-44 & 410 & EU534023 \\
\hline \multirow[t]{2}{*}{ A. divaricata A } & A. divaricata & 410 & 376 & 403 & 1189 & EU534103-07 & 410 & EU533985 \\
\hline & A. solitarynesis & - & - & - & - & - & 410 & EU534039 \\
\hline A. lovelli $\mathrm{B}$ & A. bushyensis & - & - & - & - & - & 410 & EU533975 \\
\hline \multirow{2}{*}{ A. cervicornis A } & A. palmata & 410 & 377 & 128 & 915 & EU534133-40 & 410 & EU533962-63 \\
\hline & A. cervicornis & 410 & 380 & 128 & 918 & EU534127-32 & 410 & EU533960-61 \\
\hline \multirow[t]{3}{*}{ A. muricata B } & A. grandis & 410 & - & - & - & - & 410 & EU533994 \\
\hline & A. acuminata & 410 & 375 & 128 & 913 & EU534049-51 & 410 & EU533969 \\
\hline & A. muricata & 410 & 375 & 403 & 1188 & EU534145-49 & 410 & EU534030 \\
\hline \multirow[t]{3}{*}{ A. rubusta B } & A. intermedia & - & - & - & - & - & 410 & EU533965, EU533968 \\
\hline & A. polystoma & - & - & - & - & - & 410 & EU533964 \\
\hline & A. listeri & - & - & - & - & - & 410 & EU533966 \\
\hline \multirow[t]{3}{*}{ A. selago $\mathrm{C}$} & A. yongei & - & - & - & - & - & 410 & EU534048 \\
\hline & A. tenuis & - & - & - & - & - & 410 & EU534046 \\
\hline & A. selago & 410 & $378-379$ & 555 & $1343-1344$ & EU534158-59 & 410 & EU534035-38 \\
\hline \multirow[t]{2}{*}{ A. florida $\mathrm{C}$} & A. florida & - & - & - & - & - & 410 & EU533993 \\
\hline & A. sarmentosa & - & - & - & - & - & 410 & EU534034 \\
\hline \multirow[t]{5}{*}{ A. aspera $\mathrm{C}$} & A. spicifera & - & - & - & - & - & 410 & EU534041 \\
\hline & A. millepora & 410 & $378-379$ & 554 & $1342-1343$ & EU534160-63 & 410 & EU534029 \\
\hline & A. spathulata & - & - & - & - & - & 410 & EU534040 \\
\hline & A. papillare & 410 & 376 & 553 & 1340 & EU534150-52 & - & - \\
\hline & A. pulchra & 410 & $378-80$ & $409-555$ & $1197-1343$ & EU534153-57 & 410 & EU533967 \\
\hline \multirow[t]{5}{*}{ A. hyacinthus $\mathrm{C}$} & A. anthocercis & 410 & $369-378$ & $409-416$ & $1182-1198$ & EU534052-55 & 410 & EU533970 \\
\hline & A. hyacinthus & - & - & - & - & & 410 & EU534002 \\
\hline & A. cytherea & 410 & $379-380$ & 403 & $1192-1193$ & EU534120-23 & - & - \\
\hline & A. microclados & - & - & - & - & & 410 & EU534024-25 \\
\hline & A. indonesia & 410 & $374-380$ & 403 & $1187-1193$ & EU534116-19 & 410 & EU534003 \\
\hline A. latistella $\mathrm{C}$ & A. nana & - & - & - & - & - & 410 & EU534031 \\
\hline & A. aculeus & 410 & $379-383$ & $128-403$ & $915-1193$ & EU534108-12 & - & - \\
\hline A. horrida D & A. horrida & - & - & - & - & - & 410 & EU533998-4001 \\
\hline & A. microphthalma & 410 & $374-376$ & 403 & $1187-1189$ & EU534113-15 & 410 & EU534026-28 \\
\hline & A. abrolhosensis & - & - & - & - & - & $410-411$ & EU533959 \\
\hline A. elegans D & A. elegans & - & - & - & - & - & 410 & EU533988-90 \\
\hline A. loripes D & A. granulosa & 410 & $376-382$ & $403-406$ & $1189-1195$ & EU534078-84 & 410 & EU533995-97 \\
\hline & A. jacquelineae & 410 & $382-387$ & $403-414$ & $1195-1211$ & EU534072-77 & 410 & EU534012 \\
\hline & A. loripes & 410 & $369-388$ & 403 & $1181-1202$ & EU534092-98 & $409-410$ & EU534019-22 \\
\hline & A. chesterfield & 410 & $378-384$ & 403 & $1187-1193$ & EU534066-68 & $409-410$ & EU533981-82 \\
\hline & A. caroliniana & 410 & $383-384$ & $403-406$ & $1193-1195$ & EU534069-71 & - & - \\
\hline A. echinata D & A. longicyathus & - & - & - & - & - & 410 & EU534017-18 \\
\hline & A. elseyi & 410 & $380-390$ & 403 & $1193-1203$ & EU534087-91 & 410 & EU533991-92 \\
\hline & A. carduus & - & - & - & - & - & 410 & EU533976-78 \\
\hline & A. subglabra & 410 & $376-380$ & 403 & $1188-1192$ & EU534061-65 & 410 & EU534042-45 \\
\hline & A. echinata & - & - & - & - & - & $410-411$ & EU533986-87 \\
\hline & A. batunai & - & - & - & - & - & 410 & EU533971-74 \\
\hline & A. pichoni & 410 & 369 & 403 & 1182 & EU534056-60 & 410 & EU534033 \\
\hline & A. cf divaricata & 410 & 380 & 403 & 1193 & EU534124-26 & 410 & EU533980 \\
\hline & A. dendrum & 410 & 377 & 128 & 915 & EU534099-102 & 410 & EU533983 \\
\hline & A. derawanensis & - & - & - & - & - & $410-411$ & EU533984 \\
\hline & A. kirstyae & - & - & - & - & - & 410 & EU534013-15 \\
\hline & A. $s p$. & - & - & - & - & - & 410 & EU534016 \\
\hline Isopora & I. brueggemanni & 410 & $345-353$ & $403-462$ & $1187-1234$ & EU534171-72, EU534177-80 & 410 & EU534004-5 \\
\hline & I. palifera & 410 & 364 & 462 & 1236 & EU534173 & 410 & EU534010-11 \\
\hline & I. togianensis & 410 & 364 & $456-460$ & $1230-1234$ & EU534181-83 & 410 & EU534008-9 \\
\hline & I. cuneata & 410 & 364 & $461-462$ & $1235-1236$ & EU534174-6, EU534184 & 410 & EU534006-7 \\
\hline
\end{tabular}

A, B, C, and D are the clades classified in Wallace (1999)

CaM Calmodulin, IGS intergenic spacer, - data not available 
one time Tris-acetate-EDTA (TAE) buffer. A full-length cDNA clone coding for the CaM gene of A. muricata and its genomic organization were isolated and characterized (Chiou et al. 2008). A Southern blot assay indicated that the A. muricata $\mathrm{CaM}$ gene is a single copy. A primer pair, CaME $\times 23 \mathrm{~F}: 5$ '-CTG ATC AAC TTA CAG AGG AAC A3' and CaME $\times 23 R$ : 5'-GTT GAC TTG ACC ATC AC CGT CA-3', was designed to amplify the region spanning exons 2 to 4 of the $C a M$ gene. Polymerase chain reaction (PCR) profiles for $\mathrm{CaM}$ were one cycle of $94^{\circ} \mathrm{C}$ for $3 \mathrm{~min}$; followed by 30 cycles of $94^{\circ} \mathrm{C}$ for $30 \mathrm{~s}, 50^{\circ} \mathrm{C}$ for $45 \mathrm{~s}$, and $72^{\circ} \mathrm{C}$ for $1 \mathrm{~min} 45 \mathrm{~s}$; then 1 cycle of $72^{\circ} \mathrm{C}$ for $5 \mathrm{~min}$. For $I G S$, the profile was one cycle of $94^{\circ} \mathrm{C}$ for $3 \mathrm{~min}$; followed by 30 cycles of $94^{\circ} \mathrm{C}$ for $30 \mathrm{~s}, 50^{\circ} \mathrm{C}$ for $1 \mathrm{~min}$, and $72^{\circ} \mathrm{C}$ for $1 \mathrm{~min} 30 \mathrm{~s}$; then one cycle of $72^{\circ} \mathrm{C}$ for $10 \mathrm{~min}$. PCR reactions consisted of one time PCR buffer (Invitrogen), $3 \mathrm{mM} \mathrm{MgCl} 2$ (Invitrogen), $0.2 \mathrm{mM}$ of dNTP (Promega), $0.04 \mu \mathrm{M}$ of each primer (Mission Biotech), 1\% of dimethylsulfoxide (Merck), 0.02 unit Taq DNA polymerase (Invitrogen), 10 ng coral DNA, and double-distilled $\mathrm{H}_{2} \mathrm{O}$ to $50 \mu$. The PCR products were electrophoresed in 1\% TAEagarose gels, using one time TAE buffer to assess their appropriate sizes. Then the PCR products were cloned into a TA cloning system (Promega) and transformed into Escherichia coli DH5 $\alpha$ (Promega). At least three positive colonies for each species were sequenced on an ABI PRISM 3700 DNA Analyzer (Applied Biosystems) with M13 forward and reverse primers in two directions. The mitochondrial intergenic spacer ( $m t I G S$ ) spanning between the $c y t b$ and $N A D H 2$ was amplified and directly sequenced following the protocols described in Tseng et al. (2005). DNA sequences obtained from this study have been submitted to the GenBank with their accession numbers listed in Table 1.

\section{Data Processing and Analysis}

Sequences of insert PCR fragments were assembled and manually proofread with the program SeqMan (DNASTAR). Acropora Pax-C intron sequences (van Oppen et al. 2001), $\mathrm{mt}$ control region sequences (van Oppen et al. 2001), and cytochrome $b$ sequences (van Oppen et al. 1999; Fukami et al. 2000) were obtained from GenBank for further analyses and comparisons.

Whole DNA sequences were aligned using MegAlign (DNASTAR) and were manually readjusted in MacClade (Sinauer Associates). The $p$-distances of within and among Acropora species, within Acropora, and Acropora vs. Isopora were calculated using MEGA 3.1 (Kumar et al. 2004). And the pairwise distances for the noncoding region under the Kimura 2-parameter model (Kimura 1980) were determined using MEGA 3.1. The numbers of substitutions per synonymous and nonsynonymous sites $\left(K_{\mathrm{S}}\right.$ and $K_{\mathrm{A}}$, respectively; Nei and Gojobori 1986) over protein-coding regions were analyzed using DnaSP 4.10 .9 (Rozas and Rozas 1999). The numbers of transitions and transversions for noncoding regions were analyzed using MEGA 3.1 (Kumar et al. 2004). The range of evolution rates $(\%$ $\mathrm{Mya}^{-1}$ ) from the predicted divergence time of 3.0 Mya, as the date of final closure of the Isthmus of Panama (Keigwin 1982; Duquecaro 1990; Coates and Obando 1996), to 12 Mya, the closure of Tethys sea (Bellwood et al. 2002), were used for the Caribbean and Indo-West Pacific species of Acropora in this study. The mtIGS region was highly conserved containing little information for phylogenetic construction. Phylogenetic analyses were performed using only the intron 2 and 3 regions of CaM gene. The CaM intron sequences were aligned using MEGA 4.0 (Tamura et al. 2007) and manually edited. The aligned introns that contain a region of large indels between the position 727 and position 985 was excluded from the following phylogenetic analyses. In total, 553 nucleotides of introns were used for tree construction based on the maximum likelihood (ML) and Bayesian analyses. Maximum likelihood tree were constructed using online server MultiPhyl (Thomas et al. 2007). Model was generated by the Modelgenerator (Thomas et al. 2006) and TVM $+\mathrm{G}$ model was shown as the best model. One hundred bootstrapping replicates were used to evaluate the statistic support of the ML tree. Bayesian analysis was performed using MrBayes 3.12 (Ronquist and Huelsenbeck 2003). The Markov chain Monte Carlo search was run four chains for 650,000 generations. Trees sampled every 100 generation and first 1,000 trees were discarded.

\section{Results}

Molecular Characterization of $C a M$ and $\mathrm{mt} I G S$ and Genetic Distances

A PCR fragment containing the partial exon 2 and exon 4, the full length of exon 3 , and two introns spanning the calmodulin-encoding gene was amplified for 27 species of Acropora and four species of Isopora (Table 1). The total length of exons amplified in the $C a M$ was $410 \mathrm{bp}$. The intron length was highly variable with the shortest length of $128 \mathrm{bp}$ and the longest of $555 \mathrm{bp}$ both found in intron 3 . The large fragment of insertions and deletions (indels) in the introns caused distinct length variation among the PCR products ranging from $913 \mathrm{bp}$ in A. acuminata to 1,344 in A. selago (Table 1). The mitochondrial intergenic spacer was highly conserved at 409 and $411 \mathrm{bp}$ in length. The base compositions of nuclear $\mathrm{CaM}$ introns and $\mathrm{mtIGS}$ were biased toward AT with $66.9 \%$ for $\mathrm{CaM}$ introns and $62.5 \%$ 
for $\mathrm{mt} I G S$. No apparent base composition bias was observed for CaM exons (56.4\%).

Interspecific genetic distances ( $p$-distances) were larger than those at the intraspecific level in all pairwise comparisons for both nuclear and $\mathrm{mt}$ genomes of Acropora (Table 2). The nuclear introns of both $C a M$ and $\operatorname{Pax} C$ were two-four times more diverse than the exons. The interspecific genetic distance of the CaM exon (1.12) was about 2.87 times that of the mt cytb (0.39), which is 2.43 times that of $m t I G S$ but 3.56 times slower than that of $m$ control region (3.98). In contrast, the nuclear CaM introns (3.19) evolved at a rate similar to that of the $\mathrm{mt}$ control region but 6.93 times faster than that of $m t I G S$ and 8.18 times faster than that of $\mathrm{mt} c y t b$. Similar patterns were observed when comparing the PaxC-intron with the $\mathrm{mt}$ regions (Table 2). Transitional (ts) substitutions accumulated faster than transversional (tv) substitutions in all pairwise comparisons in both nuclear and mitochondrial noncoding regions, with the largest mean ts/tv ratio being 5 in $C a M$ introns and the smallest being 1.15 in the PaxC intron (Fig. 1).

\section{Evolutionary Rate}

Separation of the Caribbean and Indo-West Pacific marine biota can be calibrated using either the closure of the Isthmus of Panama at 3 mya (Knowlton et al. 1993) or closure of the Tethyan Sea at 12 mya (Wallace 1999). Evolutionary rates based on these two calibrations are listed in Table 3. As reflected by genetic distances, evolutionary rates of nuclear introns were faster than those of exons and $\mathrm{mt}$ regions, with the exception of the $\mathrm{mt}$ control region. Overall, the evolutionary rate of nuclear (n)DNA was twofive times faster than that of mtDNA (Table 3). While the nonsynonymous substitution rate $\left(K_{\mathrm{A}}\right)$ evolved at similar tempos in CaM exons (0.006-0.023\% $\left.\mathrm{Mya}^{-1}\right)$ and $c y t b$ $\left(0.003-0.013 \% \mathrm{Mya}^{-1}\right)$, the synonymous substitution rates $\left(K_{\mathrm{S}}\right)$ of $\mathrm{CaM}$ exons $\left(0.367-1.467 \% \mathrm{Mya}^{-1)}\right.$ were 4.8 times faster than those of $c y t b\left(0.076-0.303 \% \mathrm{Mya}^{-1}\right.$; Table 4; Fig 2).

\section{CaM Introns Phylogeny}

Figure 3 shows the ML tree based on the CaM intron 2 and intron 3. Bayesian analysis yielded a similar topology to that of ML tree. Two major clades can be identified with $100 \%$ bootstrapping and 100 Bayesian probability supports. Clade I is small and can be divided in two subclades. Subclade I contains only the two Caribbean Acropora-A. palmata and $A$. cervicornis. This is the only cluster which reflects a species group based on the morphological characters (Wallace 1999). Subclade II in clade I contains A. aculeus, A. accuminata, A. dendrum, and A. digitifera. Clade II contains the remaining Acropora species used in this study. Within clade II, most species contain diverse alleles which cause the $C a M$ intron phylogeny to be not monophyletic, except for $A$. jacquelineae and $A$. divaricata. Note that the sample sizes were small for each species so that polyphyletic patterns could possibly be found for these species with the addition of new samples. Overall, species in clade II did not show concordance with groupings based on the morphological species groups.

\section{Discussion}

Our study provides parallel surveys of DNA variations in coding and noncoding regions and calibrated rates of synonymous substitutions of $\mathrm{mt}$ and nuclear genomes of

Table 2 Intraspecific, interspecific, and intergeneric mean $p$-distances (\%) and ranges (in parentheses) for coding and noncoding regions of Acropora nuclear and mitochondrial genomes

\begin{tabular}{|c|c|c|c|c|c|c|c|c|}
\hline \multirow[t]{2}{*}{$p$ distance $(\%)$} & \multicolumn{5}{|l|}{ nDNA } & \multicolumn{3}{|l|}{ MtDNA } \\
\hline & CaM exons & $C a M$ intron 2 & $C a M$ intron3 & $\begin{array}{l}\mathrm{CaM} \text { intron2+ } \\
\text { intron3 }\end{array}$ & $P a x-C^{a}$ intron & $c y t b^{\mathrm{b}}$ & $C R^{\mathrm{c}}$ & $I G S$ \\
\hline \multicolumn{9}{|l|}{ Acropora } \\
\hline Intraspecific & $0.44(0-1.6)$ & $0.76(0-5.3)$ & $0.81(0-11.5)$ & $1.15(0-8.4)$ & $1.75(0-8.9)$ & - & $0.93(0-4.5)$ & $0.21(0-0.6)$ \\
\hline Interspecific & $1.12(0-3.2)$ & $3.07(0-6.9)$ & $3.53(0-11.9)$ & $3.19(0-22.2)$ & $5.09(0-12.6)$ & $0.39(0-0.8)$ & $3.98(0.1-7.2)$ & $0.46(0-1.7)$ \\
\hline \multicolumn{9}{|l|}{ Intergeneric } \\
\hline Acropora vs. Isopora & 4.3 & 21.3 & 44.1 & 25.3 & 21.5 & 1.8 & 17.2 & 3.1 \\
\hline
\end{tabular}

- Data not available

${ }^{a}$ Acropora Pax-C intron sequences (GenBank accession nos. AF344337-AF344353, AF3443355-AF3443379, AF3443381-AF3443391, AF3443394-AF3443398, AF344400-AF344408, and AF344410-344423) published in van Oppen et al. (2001)

${ }^{\mathrm{b}}$ Acropora and Isopora cytochrome $b$ sequences (GenBank accession nos. AF099650-AF099656, AF099658-AF099659, AB033178AB033179) published in van Oppen et al. (1999) and Fukami et al. (2000)

${ }^{c}$ Acropora mt control region (GenBank accession nos. AY02618-AY026460) published in van Oppen et al. (2001) 


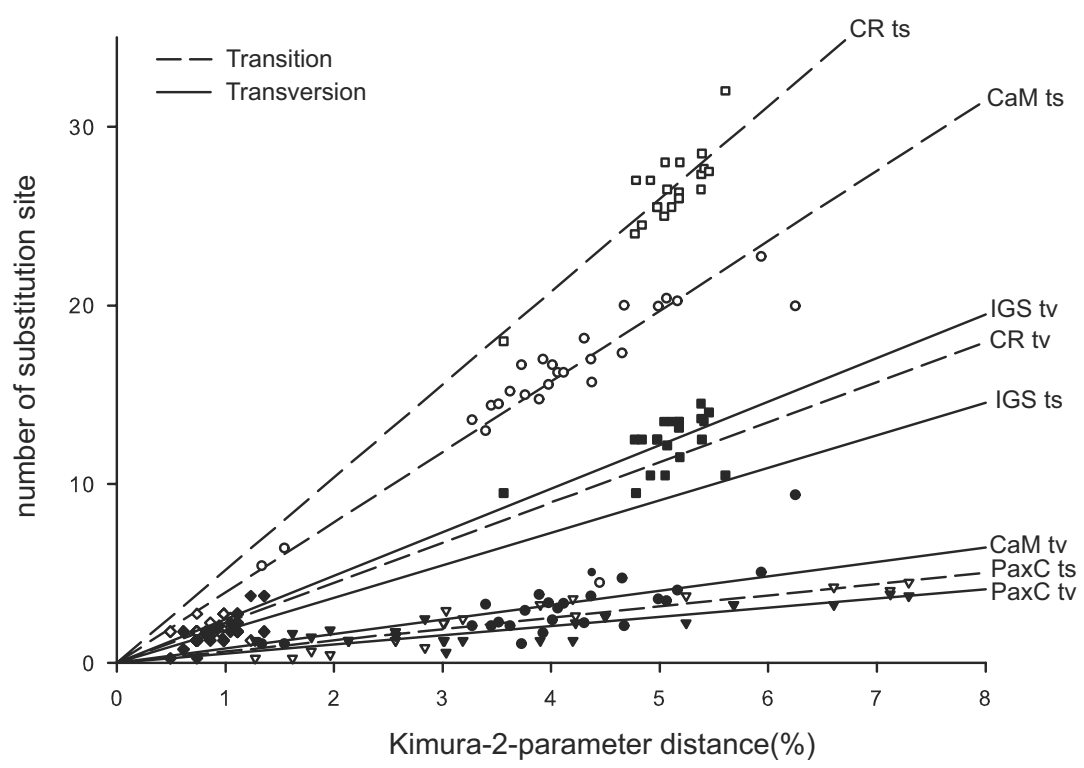

Fig. 1 Number of transitions (filled circles) and transversions (empty circles) plotted against Kimura-2-parameter (K2P) pairwise distances for the noncoding region (intron II and intron III) of $\mathrm{CaM}$. Sequences of the Pax-C intron, mitochondrial (mt) control region, and cytochrome $b$ are from GenBank that were published in van Oppen et al. (1999, 2001; GenBank accession nos. AF344337-AF344353,
AF3443355-AF3443379, AF3443381-AF3443391, AF3443394AF3443398, AF344400-AF344408, AF344410-344423; AY02618AY026460; AF099650-AF099656, and AF099658-AF099659). Regression lines between transition (dash line) and transversion (solid line) against $\mathrm{K} 2 \mathrm{P}$ distances for every coding and noncoding DNA sequences were indicated

surveys and phylogenies of closely related species. However, the coding genes, cytb and coxl, have successfully been utilized to infer the deep divergences of Atlantic and Pacific scleractinian families and genera (Fukami et al. 2004b).

Such a low level of phylogenetic variation in the coral $\mathrm{mt}$ genome is even distinct when compared to that of the nuclear genome. While vertebrate mtDNA generally is evolving up to ten times faster than single-copy genes, invertebrates exhibit similar evolutionary rates between nDNA and mtDNA (reviewed in Li 1997). In contrast, previous studies and ours indicated that coral nDNA is evolving two-five times faster than mtDNA (Fukami et al. 2000; van Oppen et al. 2001; reviewed in Shearer et al. 2002). This scenario is also supported by the comparison between allozyme heterozygosity and mtDNA sequence divergence in Banophyllia and Tubastrea corals (Hellberg 2006), microsatellites (Baum et al. 2005), and amplified fragment length polymorphisms (Fukami et al. 2004a). With the comparison between Acropora mt cytb and nuclear $C a M$ exons in this study, we confirm that the low

Table 3 Divergence rate $\left(\% \mathrm{Mya}^{-1}\right)$ of nuclear (n)DNA and mitochondrial (mt)DNA coding and noncoding regions based on the calibrations of formation of the Panama Isthmus (3 mya) and the closure of the Tethyan Sea (12 mya)

\begin{tabular}{|c|c|c|c|c|c|c|}
\hline \multirow[t]{2}{*}{ DNA region } & \multicolumn{3}{|l|}{ nDNA } & \multicolumn{3}{|l|}{ MtDNA } \\
\hline & CaM exons & $C a M$ introns & $P a x-C$ intron & $c y t b$ & $I G S$ & $C R$ \\
\hline Divergence rate $\% \mathrm{Mya}^{-1}$ & $0.081-0.325$ & $0.178-0.709$ & $0.138-0.550$ & $0.021-0.083$ & $0.036-0.143$ & $0.237-0.948$ \\
\hline
\end{tabular}


Table 4 Numbers of synonymous $\left(K_{\mathrm{S}}\right)$ and nonsynonymous $\left(K_{\mathrm{A}}\right)$ substitutions per site and the estimated rate $\left(\%\right.$ Mya $\left.^{-1}\right)$ of nonsynonymous substitutions per million years for nuclear (n)DNA CaM and mitochondrial (mt)DNA cytb of Acropora

\begin{tabular}{lcccccccc}
\hline Acropora & Site & \multicolumn{1}{c}{$L_{\mathrm{S}}$} & $K_{\mathrm{S}} \times 100$ & $L_{\mathrm{A}}$ & $K_{\mathrm{A}} \times 100$ & $K_{\mathrm{A}} / K_{\mathrm{S}}$ & $K_{\mathrm{S}}$ rate $\left(\% \mathrm{Mya}^{-1}\right)^{\mathrm{a}}$ & $K_{\mathrm{A}}$ rate $\left(\% \mathrm{Mya}^{-1}\right)^{\mathrm{a}}$ \\
\hline CaM & 408 & 84.08 & 8.80 & 323.92 & 0.14 & 0.016 & $0.367-1.467$ & $0.006-0.023$ \\
$c y t b^{\mathrm{a}}$ & 954 & 231.74 & 1.82 & 722.26 & 0.08 & 0.044 & $0.076-0.303$ & $0.003-0.013$ \\
\hline
\end{tabular}

$L_{\mathrm{S}}$ and $L_{\mathrm{A}}$ are the numbers of synonymous and nonsynonymous sites, respectively

$T$ Divergent time

${ }^{\mathrm{a}}\left(K_{\mathrm{S}}\right.$ or $\left.K_{\mathrm{A}} / 2 T\right)$, where $T$ is 3.0-12.0 Mya of the divergence time for Caribbean and Indo-West Pacific species of Acropora

variation in both coding and noncoding DNA appears to be a characteristic of the coral $\mathrm{mt}$ genome.

Our estimation of the rate difference between nDNA and mtDNA might be still low. In this study, the CaM and its introns served as the nuclear candidate for the comparison. The $C a M$, a calcium-binding protein, exists widely in eukaryotic organisms and is one of the ancient genes that has been highly conserved at the amino acid level in eukaryotes (Friedberg and Rhoads 2001). Thus, our estimation of the nDNA evolutionary rate might have been conservative. In contrast, a recent study indicated that Acropora possesses extremely highly heterogeneity in its ribosomal RNA genes (Wei et al. 2006), suggesting that the faster-evolving genes remain to be scanned from the nuclear genome. Once these genes are found, the rate difference of nDNA compared to that of mtDNA is expected to increase. An available EST library for $A$. millepora (Kortschak et al. 2003) can serve this purpose.
Low Rates of Synonymous Substitution in the Coral mt Genome

The slow rate of synonymous substitutions $\left(K_{\mathrm{S}}\right)$ has been documented in the dendrophilid corals for two genera, Tubastrea and Balanophyllia, with independent fossil records extending back over 50 million years showing the rate of COI $K_{\mathrm{S}}$ of $0.056 \% \mathrm{Mya}^{-1}$ (Hellberg 2006). Acropora cytb $K_{\mathrm{S}}\left(0.076 \% \mathrm{Mya}^{-1}\right)$ is compatible with that of dendrophilid COI $K_{\mathrm{S}}$ if divergence of the Caribbean and Indo-West Pacific Acropora is calibrated by the closure of the Tethyan before $12 \mathrm{Mya}$. It increases to $0.303 \% \mathrm{Mya}^{-1}$ if the divergence time is calibrated by the closure of the Isthmus of Panama at 3 Mya (van Oppen et al. 1999). Although there is a four-fold difference in these two calibrations, Acropora cytb $K_{\mathrm{S}}$ is still 50 to 100 times slower than those reported for most animals (Govindarajan et al. 2005; Hellberg 2006). In contrast, the nonsynon-

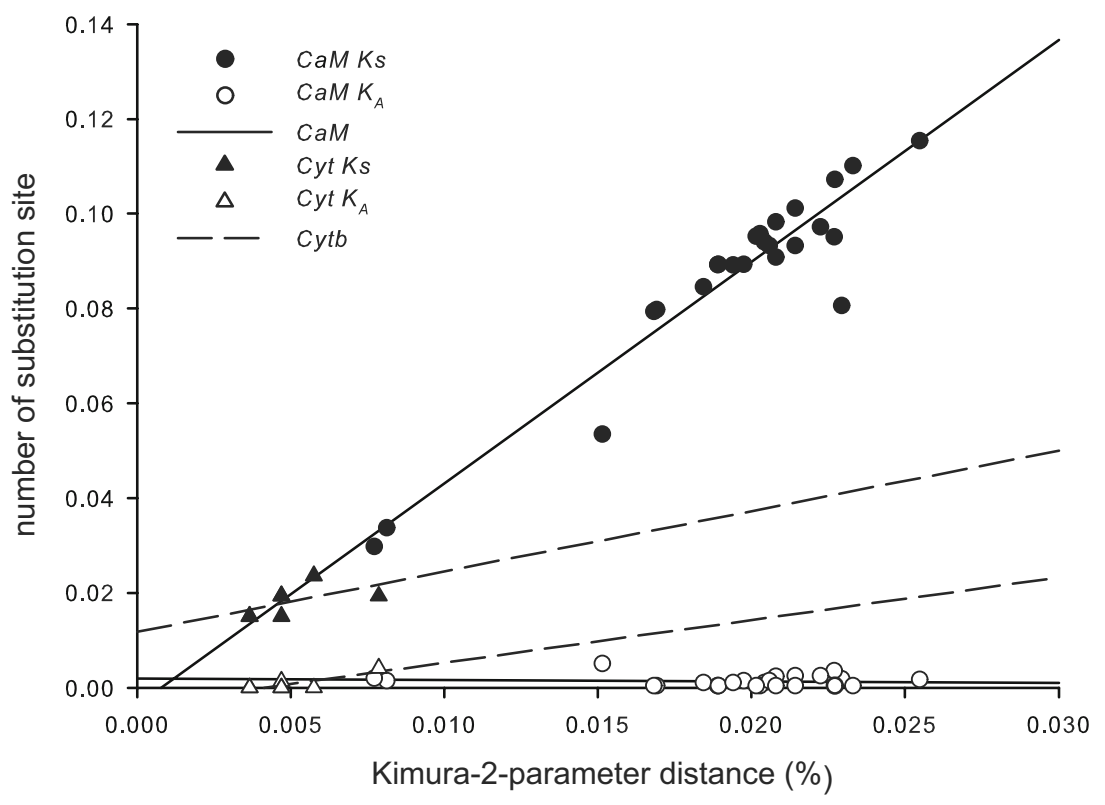

Fig. 2 Number of synonymous $\left(K_{\mathrm{S}}\right)$ and nonsynonymous $\left(K_{\mathrm{A}}\right)$ substitutions per site for $C a M$ and $c y t b$ plotted against Kimura-2parameter pairwise distances. Circles with a rigid regression line and triangles with a dotted regression line are for CaM and cytb, respectively. Filled symbols are $K_{\mathrm{S}}$, and the empty ones are $K_{\mathrm{A}}$. Regression lines of cytb's $K_{\mathrm{S}}$ and $K_{A}$ (dash line) and CaM's $K_{\mathrm{S}}$ and $K_{\mathrm{A}}$ (solid line) against $\mathrm{K} 2 \mathrm{P}$ distances were indicated 

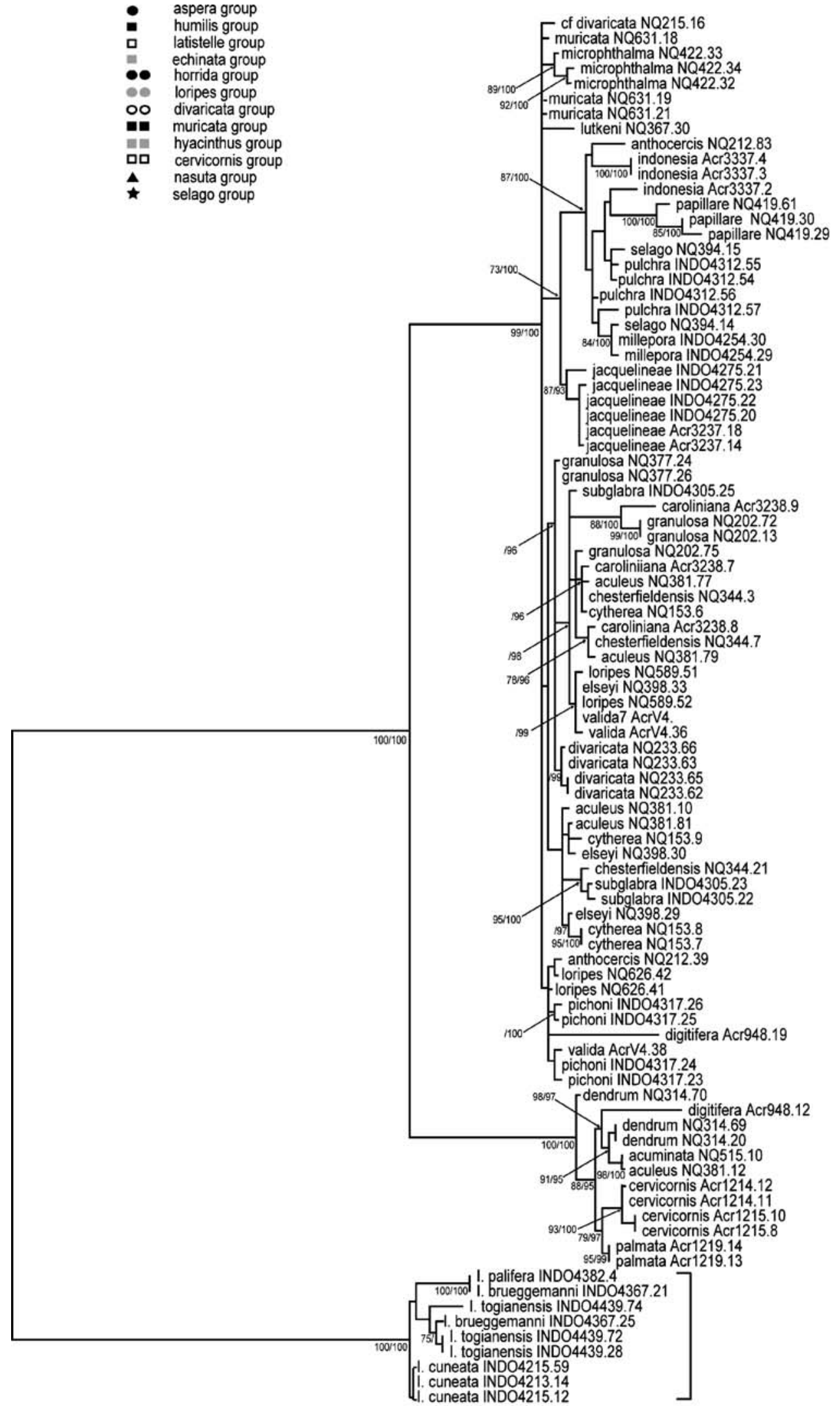

muricata NQ631.18

microphthalma NQ422.33

microphthalma NQ422.34

921100 -muricata Nhthalma

-muricata NQ631.19

- muricata NQ631.21 30

anthocercis NQ212.83

anthocercis NQ212.83
indonesia Acr 3337.4
indonesia Acr3337.3

87/100 indonesia A 3337,3

- papillare NQ419.61

85/100 papillare NQ419.30

L selago NQ394.15

73/100 - pulchra INDO4312.55 -pulchra INDO4312.56 pulchra INDO4312.57 - pulchra NDO4312.57 84/100 millepora INDO4254.30

millepora INDO4254.29

— jacquelineae INDO4275.21

r jacquelineae INDO4275.23

acquelineae INDO4275.20

acquelineae Acr3237.18

acquelinea Acr3237.14

granulosa NQ377.24

granulosa NQ377.24

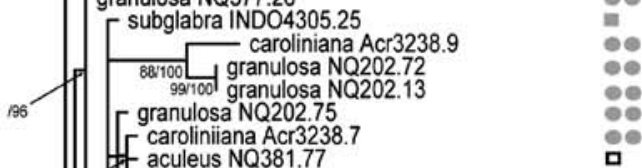

- aculeus NQ381.77

chesterfieldensis NQ344.3

${ }_{96} 1$ Lytherea NQ153.6

96 - caroliniana Acr3238.8

chesterfieldensis NQ344.7

198 L 1 aculeus NQ381.79

7096 - loripes NQ589.51

$70 / 96$

loripes N0589.52

cytherea NQ153.

C chesterfieldensis NQ344.2

[ subla

95/100 cytherea NQ153.

valida $\mathrm{Acr}$

8897 dendrum NQ314.70

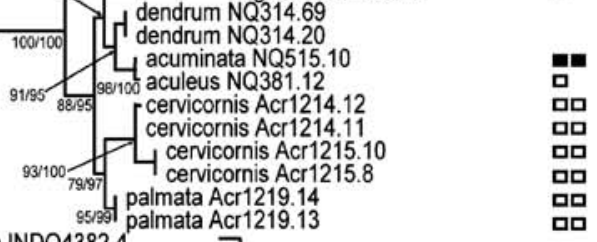


Fig. 3 Maximum likelihood tree using $\mathrm{TVM}+\mathrm{G}$ model of the $\mathrm{CaM}$ introns. Value before the slash on the branch indicated the bootstrap values (1,000 replicates) and values below 70 was not shown. Value after the slash on the branch indicated the credibility values of Bayesian method and value below 95 was not shown

ymous substitution $\left(K_{\mathrm{A}}\right)$ of coral mtDNA (dendrophilids, $0.019 \% \mathrm{Mya}^{-1}$; Acropora: $\left.0.003-0.013 \% \mathrm{Mya}^{-1}\right)$ is similar to those of other animals and plants $\left(0-0.056 \% \mathrm{Mya}^{-1}\right.$; Hellberg 2006). In a summary by Hellberg (2006), the low synonymous substitution rate in the $\mathrm{mt}$ genome evolved in two different modes: one is slow relative to nDNA and with little bias toward transitions, while the other is faster relative to nDNA and often exhibits a high-transition bias. The mt genomes of flowering plants, fungi, sponges, and anthozoans belong to the former mode, and the rest of the animals belong to the latter mode. The direction of the rate of evolution always switches from the slow to the fast mode and has occurred at least four times, twice in flowering plants, once in cnidarians, and once in bilateral animals (Hellberg 2006).

Constraints on codon usage in mitochondria from the reduced rate of synonymous substitutions can be explained by constraints on synonymous codon choices (Sharp and $\mathrm{Li}$ 1987). Nevertheless, constructions for the low variation of mitochondrial noncoding regions (about 3.8 times less than nDNA in this study) are intriguing. The lack of variation and the slow divergence rate in coral mitochondria are probably due to anthozoans' mitochondrial functionally mismatched repair system (Brown et al. 1982; Clayton 1982; Moritz et al. 1987; Pont-Kingdon et al. 1998) and functional constraints, which influence and decrease the substitution rate and the accumulation of mitochondrial genomic mutations. Several factors may also play roles in influencing the mitochondrial nucleotide substitution rate such as the metabolic rate (Martin et al. 1992), the base composition of silent codon positions (Wolfe et al. 1987), the effective population size, and the generation time (Wu and Li 1985; Li et al. 1987). The small effective population size of mtDNA genes may have suffered a bottleneck resulting in the founder effect (Wright 1931; Nei et al. 1975), which would lead to the phenomenon of low variations within the mitochondrial gene especially with the long generation time of corals. This scenario is exemplified by Tubastrea coccinea collected from the Hawaii and Caribbean that their coxI gene differs by only a single nonsynonymous substitution (Hellberg 2006). The Caribbean $T$. coccinea might represent a recently introduced species from the Pacific (Cairns 2000). This can also explain the low genetic diversity of mtDNA and the maternally inherited and haploid genome, relative to nDNA diversity, in the three Caribbean Acropora species, which might have suffered a bottleneck since last isolation at least
3 Mya due to the final closure of the Isthmus of Panama (Coates and Obando 1996). Nevertheless, this is unlikely to be the major explanation for the wide range of Acropora taxa in the Indo-Pacific.

\section{Phylogenetic Inference of CaM Introns}

Phylogenetic analyses using CaM intron DNA sequences produced two major clades for Acropora, one contained two Caribbean species, A. cervicornis and A. palmata, and four other Indo-Pacific species, and the other clades included rest 26 species. Most of the species examined in the present study were not included in the two published phylogenies by minicollagen intron (Hatta et al. 1999; Fukami et al. 2003) and PaxC46/47 intron (van Oppen et al. 2001), thus providing little information for comparison. Nevertheless, reproductive isolation by spawning time and divergence of the Caribbean vs. Indo-Pacific Acropora may be still elucidated further. First, the basal group of the Pax$C 46 / 47$ intron tree was composed of A. longicyathus, $A$. intermedia, and A. tenuis (van Oppen et al. 2001). These three species have been proposed to be the early spawning species which provide the reproductive isolation to the other Acropora (van Oppen et al. 2001). Fukami et al. (2003) also observed A. tenuis, A. donei, A. yongi, A. austere, $A$. verweyi, and $A$. vaughani as the early spawners using minicollagen intron. Unfortunately, these species were not assessed by the CaM intron, thus, their possible positions in the CaM phylogeny remains uncertained. Future examining $C a M$ intron of these species provides the opportunity to examine the scenario reproductive isolation through differentiation of spawning. Second, the position of the Caribbean species is quite different between the CaM intron tree and that of the PaxC46/47 intron. While the Caribbean Acropora stand at the basal position of the genus Acropora in CaM intron tree, they were clustered with $A$. cytherea in the third clade in the Pax-C46/47 intron tree (van Oppen et al. 2001). Interestingly, the basal position of the Caribbean Acropora is supported by the phylogeny of mitochondrial control region (van Oppen et al. 2001). Although incongruence between nuclear and mitochondrial gene trees are ascribed to the incomplete lineage sorting of markers, some implications of effect of major vicariant event on the evolution of Acropora can still be elucidated.

Similar Tempos of Mitochondrial vs. Nuclear Evolutionary Rates between Acropora and Flowering Plant Genomes: Similar Life History Traits between Acropora and Plants

Although mt genomes of corals (and anthozoans in general) have group I introns and intergenic spacers like those in some plants and fungi, the mt genomes of corals and 
flowering plants differ in several aspects. Firstly, the anthozoan mt genome, like that of most other animals, is small (16-20 kb; van Oppen et al. 1999; Fukami and Knowlton 2005; Tseng et al. 2005; Medina et al. 2006; Chen et al. 2008), while the plant $\mathrm{mt}$ genome is relatively large (40-250 kb; Li 1997). Secondly, the coral mt genome contains relatively consistent gene numbers (13 proteincoding, two rRNA, and two tRNA genes) and arrangements (Medina et al. 2006; Chen et al. 2008), while plant mt genomes undergo frequent rearrangements and contain large numbers of potential genes: for example, the liverwort (Marchantia polymorpha) contains 94 possible genes (Li 1997). Nevertheless, the synonymous substitution rate of the Acropora mt cytb gene is evolving 4.8 times more slowly than $\mathrm{CaM}$ exons in the nuclear genome, a tempo similar to that reported in comparisons of flowering plant $\mathrm{mt}$ and nuclear genomes (Wolfe et al. 1987; reviewed in Li 1997), where the synonymous substitution rate of the $\mathrm{mt}$ $c y t b$ gene is at least five times slower than $C a M$ exons in the nuclear genome. Plants $\mathrm{mt}$ genome was documented evolving slowly in DNA sequences (Palmer and Herbon 1988). Wolfe et al. (1987) showed synonymous substitution rate in plants mtDNA is slower than in mammalian mt DNA and only as half as faster in plants nuclear DNA. Substitution rate in plants mtDNA slower than nuclear DNA has been confirmed in subsequent studies (Gaut 1988; Muse 2000).

This coincidence is unexpected and might reflect a similarity in life history traits between Acropora, or corals in general, and plants. Recent studies have confirmed that hermaphroditic coral species with broad dispersal potentials are either completely or almost completely self-incompatible, while species with limited dispersal potentials have high, but variable, rates of selffertilization (Heyward and Babcock 1986; Black et al. 1991; Miller and Mundy 2003). This interspecific variation in coral mating systems is similar to that found in terrestrial plants (reviewed in Carlon 1999). The influence of life history traits on the rate of molecular evolution is exemplified by a correlation between body size (i.e., metabolic rate) and rate of molecular evolution in vertebrates: smaller species tend to have faster rates of molecular evolution (Martin and Palumbi 1993). However, a recent study showed no evidence of any influence of body size on invertebrate substitution rates, and it was concluded that the vertebrate body size effect is a special case, which cannot simply be extrapolated to the rest of the animal kingdom (Thomas et al. 2006). The scenario of correlating mating systems and rates of molecular evolution in corals can be further tested by examining more genes across different taxa. The challenge now is to consider whether this similarity is coincidental or actually reflects genuine similarities in genetically programmed life functions of corals and plants. Both have modular growth and lifestyle, in which growth, reproduction and many physiological functions are performed by repeated and interconnected modules. Coordination among modules is an important aspect of the way that geometry and architecture of both plants and corals are achieved, and physiological processes are maximized (Dauget 1991; Donoghue 2005). In Acropora, in particular, the development of an axial mode of growth leading to various shape possibilities has been noted (Dauget 1991; Vermeij 1973). Plants and corals share some of the features such as this, which have been described as "key innovations", leading to enhance evolutionary rates in higher taxa (Vermeij 1973).

In conclusion, our study provides comparative DNA sequences of protein-coding and noncoding regions of coral $\mathrm{mt}$ and nuclear genomes and supports evidence from other coral studies that the $\mathrm{mt}$ genome is evolving at a slower tempo compared to the nuclear genome. This is similar to findings in plant genomes that nuclear genomes are evolving the fastest, followed by chloroplast genomes, and last $\mathrm{mt}$ genomes. Furthermore, the evolutionary tempos are also similar between corals and plants in that nuclear genomes are evolving at least five times faster than the mitochondrial counterparts.

Acknowledgements Many thanks to Grant Burgess and two anonymous referees for constructive comments; Yaoyung Chuang, Cheinwei Chen, and members of the Coral Reef Evolutionary Ecology and Genetics Lab, Research Center for Biodiversity, Academia Sinica (RCBAS), for assistance with field work, and the Penghu Marine Life Propagation Center, a facility of Penghu County, which provided facilities and hospitality during the 2005 coral spawning season in Penghu. C.-Y. Chiou for the receipt of Academia Sinica Postdoctoral Fellowship (2005-2007). This work was supported by NSC grants and Academia Sinica Thematic and Genomics Grants (2002-2004, 20062007) to CAC. This is the Coral Reef Evolutionary Ecology and Genetics Lab, RCBAS contribution no. 45.

\section{References}

Babcock RC, Bull GD, Harrison PL, Heyward AJ, Oliver JK, Wallace CC, Willis BL (1986) Synchronous spawning of 105 coral species on the Great Barrier Reef. Mar Biol 90:379-394

Baums IB, Miller MW, Hellberg ME (2005) Regionally isolated populations of an imperiled Caribbean coral, Acropora palmata. Mol Ecol 14:1377-1390

Bellwood DR, Wainwright PC, Fulton CJ, Hoey A (2002) Assembly rules and functional groups at global biogeographical scales. Funct Ecol 16:557-562

Black KP, Moran PJ, Hammond LS (1991) Numerical-models show coral reefs can be self-seeding. Mar Ecol Prog Ser 74(1):1-11

Brown WM, Prager EM, Wang A, Wilson AC (1982) MitochondrialDNA sequences of primates tempo and mode of evolution. J Mol Evol 18:225-239

Cairns S (2000) A revision of the shallow-water zooxanthellate Scleractinia of the Western Atlantic. Stud Nat Hist Caribb Reg $75: 1-240$

Carlon DB (1999) The evolution of mating systems in tropical reef corals. Trends Ecol Evol 14:491-495 
Chen CA, Yu J-K (2000) Universal primers for amplification of mitochondrial small subunit ribosomal RNA-encoding gene in scleractinian corals. Mar Biotech 2:146-153

Chen C, Dai C-F, Chiou C-Y, Plathong S, Chen CA (2008) The Complete mitochondrial genomes of needle corals, Seriatopora spp (Scleractinia; Pocilloporidae): idiosyncratic atp8 gene, duplicated tRNA-Trp, and the hypervariable regions for species phylogenies and recently diverged populations. Mol Phylogen Evol 46:19-33

Chiou C-Y, Chen I-P, Chen C-H, Wei NV, Wu H, Wallace CC, Chen CA (2008) Analysis of Acropora muricata calmodulin (CaM) indicates scleractinian coral possess the ancestral exon/intron organization of eumetazoan CaM gene. J Mol Evol 66:317-324 doi:10.1007/s00239-008-9084-6

Clayton DA (1982) Replication of animal mitochondrial-DNA. Cell 28:693-705

Coates AG, Obando JA (1996) The geological evolution of the central American Isthmus. University of Chicago Press, Chicago

Dauget JM (1991) Application of tree architectural models to reefcoral growth forms. Mar Biol 111:157-165

Donoghue MJ (2005) Key innovations, convergence, and success: macroevolutionary lessons from plant phylogeny. Paleobiology 31:77-93

Duquecaro H (1990) Neogene stratigraphy, paleoceanography and paleobiogeography in northwest south-America and the evolution of the Panama seaway. Palaeogeogr Palaeoclimateol Palaeoecol 77:203-234

Friedberg F, Rhoads AR (2001) Evolutionary aspects of calmodulin. IUBMB Life 51:215-221

Fukami H, Knowlton N (2005) Analysis of complete mitochondrial DNA sequences of three members of the Montastraea annularis coral species complex (Cnidaria,Anthozoa, Scleractinia). Coral Reefs 24:410-417

Fukami H, Omori M, Hatta M (2000) Phylogenetic relationships in the coral family Acroporidae, reassessed by inference from mitochondrial genes. Zool Sci 17:689-696

Fukami H, Omori M, Shimoike T, Hayashibara T, Hatta M (2003) Ecological and genetics aspects concerned with reproductive isolation by differential spawning timing in Acropora corals. Mar Biol 142:679-684

Fukami H, Budd AF, Levitan DR, Jara J, Kersanach R, Knowlton N (2004a) Geographic differences in species boundaries among members of the Montastraea annularis complex based on molecular and morphological markers. Evolution 58:324-337

Fukami H, Budd AF, Paulay G, Sol Cava A, Chen CA, Iwao K, Knowlton N (2004b) Conventional taxonomy obscures deep divergence between Pacific and Atlantic corals. Nature 427:832-835

Gaut BS (1998) Molecular clocks and nucleotide substitution rates in higher plants. Evol Biol 30:93-120

Govindarajan AF, Halanych KK, Cunningham CW (2005) Mitochondrial evolution and phylogeography in the hydrozoan Obelia geniculata (Cnidaria). Mar Biol 146:213-222

Hatta M, Fukami H, Wang WQ, Omori M, Shimoike K, Hayashibara T, Ina Y, Sugiyama T (1999) Reproductive and genetic evidence for a reticulate evolutionary history of mass-spawning corals. Mol Biol Evol 16:1607-1613

Harrison PL, Babcock RC, Bull GD, Oliver JK, Wallace CC, Willis BL (1984) Mass spawning in tropical reef corals. Science 223:1186-1189

Hellberg ME (1994) Relationships between inferred levels of gene flow and geographic distance in a philopatric coral, Balanophyllia elegans. Evolution 48:1829-1854

Hellberg ME (1995) Stepping-stone gene flow in the solitary coral Balanophyllia elegans - equilibrium and nonequilibrium at different spatial scales. Mar Biol 123:573-581

Hellberg ME (2006) No variation and low synonymous substitution rates in coral mtDNA despite high nuclear variation. BMC Evol Biol 6:24-32
Heyward AJ, Babcock RC (1986) Self-fertilization and crossfertilization in scleractinian corals. Mar Biol 90:191-195

Keigwin L (1982) Isotopic paleo-oceanography of the Caribbean and East Pacific - role of Panama uplift in late Neogene time. Science 217:350-352

Kimura M (1980) A Simple method for estimating evolutionary rates of base substitutions through comparative studies of nucleotidesequences. J Mol Evol 16:111-120

Knowlton N, Weigt LA, Solórzano LA, Mills DK, Bermingham E (1993) Divergence in proteins, mitochondrial DNA, and reproductive compatibility across the Isthmus of Panama. Science 260:1629-1632

Kortschak RD, Samuel G, Saint R, Miller DJ (2003) EST analysis of the cnidarian Acropora millepora reveals extensive gene loss and rapid sequence divergence in the model invertebrates. Curr Biol 13:2190-2195

Kumar S, Tamura K, Nei M (2004) MEGA3: integrated software for molecular evolutionary genetics analysis and sequence alignment. Brief Bioinform 5:150-163

Li WH (1997) Molecular evolution. Sinauer, Sunderland, MA

Li WH, Tanimura M, Sharp PM (1987) An evaluation of the molecular clock hypothesis using mammalian DNA Sequences. J Mol Evol 25:330-342

Martin AP, Palumbi SR (1993) Body size, metabolic rate, generation time and the molecular clock. Proc Natl Acad Sci U S A 90:4087-4091

Martin AP, Naylor GJP, Palumbi SR (1992) Rates of mitochondrial DNA evolution in sharks are slow compared with mammals. Nature 357:153-155

Medina M, Weil E, Szmant AM (1999) Examination of the Montastraea annularis species complex (Cnidaria: Scleractinia) using ITS and COI sequences. Mar Biotech 1:89-97

Medina M, Collins AG, Takaoka TL, Kuehl JV, Boore JL (2006) Naked corals: skeleton loss in Scleractinia. Proc Natl Acad Sci U S A 103:9096-9100

Miller K, Mundy C (2003) Rapid settlement in broadcast spawning corals: implications for larval dispersal. Coral Reefs 22:99-106

Moritz C, Dowling TE, Brown WM (1987) Evolution of animal mitochondrial DNA relevance for population biology and systematics. Ann Rev Ecol Syst 18:269-292

Muse SV (2000) Examining rates and patterns of nucleotide substitution in plants. Plant Mol Biol 42:25-43

Nei M, Gojobori T (1986) Simple methods for estimating the numbers of synonymous and nonsynonymous nucleotide substitutions. Mol Biol Evol 3:418-426

Nei M, Maruyama T, Chakraborty R (1975) Bottleneck effect and genetic variability in Populations. Evolution 29:1-10

Palmer JD, Herbon LA (1988) Plant mitochondrial DNA evolves rapidly in structures, but slowly in sequence. J Mol Evol 28:87-97

Palmer JD, Adams KL, Cho Y, Parkinson CL, Qiu Y-L, Song K (2000) Dynamic evolution of plant mitochondrial genomes: mobile genes and introns and highly variable mutation rates. Proc Natl Acad Sci U S A 97:6960-6966

Pont-Kingdon G, Okada NA, Macfarlane JL, Beagley CT, WatkinsSims CD, Cavalier-Smith T, Clark-Walker GD, Wolstenholme DR (1998) Mitochondrial DNA of the coral Sarcophyton glaucum contains a gene for a homologue of bacterial MutS: A possible case of gene transfer from the nucleus to the mitochondrion. J Mol Evol 46:419-431

Ronquist F, Huelsenbeck JP (2003) MRBAYES 3: Bayesian phylogenetic inference under mixed models. Bioinformatics 19:15721574

Rozas J, Rozas R (1999) DnaSP version 3: an integrated program for molecular population genetics and molecular evolution analysis. Bioinformatics 15:174-175 
Sharp PM, Li WH (1987) The codon adaptation index-a measure of directional synonymous codon usage bias, and its potential applications. Nuclei Acids Res 15:1281-1295

Shearer TL, van Oppen MJH, Romano SL, Worheide G (2002) Slow mitochondrial DNA sequence evolution in the Anthozoa (Cnidaria). Mol Ecol 11:2475-2487

Snell TL, Foltz DW, Sammarco PW (1998) Variation in morphology vs. conservatism of a mitochondrial gene in Montastrea cavernosa (Cnidaria, Scleractinia). Gulf Mexico Sci 70:188-195

Tamura KDJ, Nei M, Kumar S (2007) MEGA4: molecular evolutionary genetics analysis (MEGA) software version 4.0. Mol Biol Evol 24:1596-1599

Thomas MK, Christopher JC, Melissa MP, Thomas JN, James OM (2006) Assessment of methods for amino acid matrix selection and their use on empirical data shows that ad hoc assumptions for choice of matrix are not justified. BMC Evol Biol 6:29

Thomas MK, Thomas JN, James OM (2007) MultiPhyl: a highthroughput phylogenomics webserver using distributed computing. Nucleic Acids Res 35:W33-W37

Tseng C-C, Wallace CC, Chen CA (2005) Mitogenomic analysis of Montipora cactus and Anacropora matthai (Cnidaria; Scleractinia; Acroporidae) indicates an unequal rate of mitochondrial evolution among Acroporidae corals. Coral Reefs 24:502-508

van Oppen MJH, Willis BL, Miller DJ (1999) Atypically low rate of cytochrome $\mathrm{b}$ evolution in the scleractinian coral genus Acropora. Proc R Soc Lond B 266:179-183

van Oppen MJH, McDonald BJ, Willis B, Miller DJ (2001) The evolutionary history of the coral genus Acropora (Scleractinia, Cnidaria) based on a mitochondrial and a nuclear marker: Reticulation, incomplete lineage sorting, or morphological convergence? Mol Biol Evol 18:1315-1329

Vermeij GJ (1973) Adaptation, versatility, and evolution. Syst Zool 22 (4):466-477
Veron JEN (1993) A biogeographic database of hermatypic corals. Species of the central Indo-Pacific genera of the world. Aust Inst Mar Sci 10:9

Wallace CC (1999) Staghorn corals of the world: a revision of the genus Acropora. CSIRO, Collingwood, Victoria, Australia

Wallace CC, Chen CA, Fukami H, Muir PR (2007) Recognition of separate genera within Acropora based on new morphological, reproductive and genetic evidence from Acropora togianensis, and elevation of the subgenus Isopora Studer, 1878 to genus (Scleractinia: Astrocoeniidae; Acroporidae). Coral Reefs 26:231-239

Wei NWV, Wallace CC, Dai CF, Pillay KRM, Chen CA (2006) Analyses of the ribosomal internal transcribed spacers (ITS) and the $5.8 \mathrm{~S}$ gene indicate that extremely high rDNA heterogeneity is a unique feature in the scleractinian coral genus Acropora (Scleractinia; Acroporidae). Zool Stud 45:404-418

Willis BL, Babcock RC, Harrison PL, Oliver JK, Wallace CC (1985) Patterns in the mass spawning of corals on the Great Barrier Reef from 1981 to 1984 . Proc 5th Int Coral Reef Symp 4:343348

Willis BL, Babcock RC, Harrison PL, Wallace CC (1997) Experimental hybridisation and breeding incompatibilities within the mating systems of mass spawning reef corals. Coral Reefs 16:553-565

Willis BL, van Oppen MJH, Miller DJ, Vollmer SV, Ayre DJ (2006) The role of hybridization in the evolution of reef corals. Ann Rev Ecol Evol Syst 37:489-517

Wolfe KH, Li WH, Sharp PM (1987) Rates of nucleotide substitution vary greatly among plant mitochondrial, chloroplast, and nuclear DNAs. Proc Natl Acad Sci U S A 84:9054-9058

Wright S (1931) Evolution in Mendelian populations. Genetics 16:0097-0159

Wu CI, Li WH (1985) Evidence for higher rates of nucleotide substitution in rodents than in man. Proc Natl Acad Sci U S A 82:1741-1745 